\title{
Enhanced Anticancer Potency of Hydroxytyrosol and Curcumin by PLGA-PAA Nano-Encapsulation on PANC-1 Pancreatic Cancer Cell Line
}

\section{Mahdieh Farhoudi \\ Tabriz Azad University}

Behrouz Shadman

Ege University

\section{Reza Chavoshi}

Islamic Azad University Tabriz Branch

Nasrin Seyyedsani

Tabriz Azad University

\section{Elnaz Aghaei}

Islamic Azad University Arsanjan

\section{Elham Taheri}

Tabriz University of Medical Sciences

\section{Pouya Goleij}

Sana Institute

\section{Saba Hajazimian}

Tabriz University of Medical Sciences

\section{Vahidreza Karamad}

Ege University: Ege Universitesi

Alireza Isazadeh ( $\boldsymbol{\sigma}$ isazadeh.alireza73@gmail.com )

Tabriz University of Medical Sciences

\section{Behzad Baradaran}

Tabriz University of Medical Sciences

\section{Research article}

Keywords: Pancreatic Cancer, PLGA-PAA copolymer, Hydroxytyrosol, Curcumin, Apoptosis

Posted Date: November 16th, 2020

DOI: https://doi.org/10.21203/rs.3.rs-108173/v1 
License: (c) (i) This work is licensed under a Creative Commons Attribution 4.0 International License. Read Full License 


\section{Abstract}

Background: Pancreatic cancer (PC) is a highly aggressive malignancy associated with low survival rates. Many chemotherapeutic regimens have been investigated for advanced unresectable and metastatic PC, but with only minimal improvement in survival and prognosis. The present study aimed to investigate the anti-cancer function of free and nano-encapsulated hydroxytyrosol (Hyd) and curcumin (Cur), and its combinations (Hyd-Cur) on the PANC-1 cell line.

Methods: The poly lactide-co-glycolide-co-polyacrylic acid (PLGA-co-PAA) nano-encapsulated Hyd and Cur were synthesized, and MTT assay was performed to evaluate cytotoxic effects of free and nanoencapsulated Hyd, Cur, and Hyd-Cur. Moreover, effects of free and nano-encapsulated Hyd, Cur, and HydCur were evaluated on viability, migration, morphological alterations, colony formation, and apoptosis on PANC-1 cell line. The mRNA expression levels of MMP2, MMP9, BAX, BCL-2, and Cas9 genes were assessed after treated PANC-1 cells with free and nano-encapsulated Hyd, Cur, and Hyd-Cur.

Results: The obtained results showed that free and nano-encapsulated Hyd, Cur, and Hyd-Cur treatments significantly decreased the viability, migration, and colony formation in the PANC-1 cells. Furthermore, apoptosis rates in PANC-1 cells were increased in a concentration and time dependent manner in all of the treatment groups. Moreover, anti-proliferative activity of nano-encapsulated Hyd-Cur was significantly more than other treatments.

Conclusions: According to our results, Hyd-Cur combination and nano-encapsulation therapy exerts more profound apoptotic and anti-proliferative effects on PANC-1 cell line than free Hyd or Hyd monotherapy.

\section{Background}

Pancreatic cancer (PC) is an invasive neoplasm and one of the most cause of cancer death worldwide [1]. Surgery is a common method for treatment of PC, because most patients with $\mathrm{PC}$ are diagnosed at a late stage, and thus a small number of patients can benefit from surgery [2]. The Gemcitabine-based chemotherapy has been used as another treatment method for patients with advanced PC. However, chemotherapy is associated with various side effects, decreased life quality, and poor survival [3]. In order to obtain appropriate treatment strategies for the management of PC and other cancer types, new alternative therapies including minimally toxic natural compounds, such as hydroxytyrosol (Hyd) and curcumin (Cur), have been considered [4].

Cur is a natural polyphenolic compound isolated from turmeric (Curcuma longa), which used commonly as a dietary supplement [5]. This compound indicates several beneficial drug effects, including antioxidant, anti-inflammatory, and anti-microbial activity. Moreover, anti-cancer activity of Cur on various types of cancer has been reported through modifying several signaling pathways $[6,7]$. Therefore, the underlying mechanisms of anti-cancer activity of Cur has recently been studied [8,9]. Evidence suggests that Cur has an inhibitory effect on proliferation of cancer cells through targeting several cancer-related pathways, such as apoptosis and cell cycle [10]. 
Olives are a nutrient with antioxidant, anti-inflammatory and anti-cancer effects. Hyd is one of the important compounds of olive oil that indicates appropriate anti-tumor activity through modification of several cancer-related pathways, such as cell cycle inhibition as well as apoptosis induction $[11,12]$. The anti-cancer activity of Hyd has been reported against several human cancers, and roles of several involved mechanisms has been evaluated [13-15]. However, our knowledge from underlying mechanisms of anti-proliferative activity of Hyd against PC cells is very limited.

The polyethylene co-glycolic acid (PLGA) is one of the most appropriate polymers for drug delivery due to reduced toxicity [16]. The short half-life and low solubility in aquatic and physiological environments cause to limited use of Hyd and Cur in cancer treatment [17]. The PLGA nanoparticles protect various drugs and introduce drugs into the cells through endocytosis and modification of Clathrin [18]. Recently, nano-encapsulation has been introduced as one of the most important methods to increase efficiency of various drugs and natural compounds [19]. The nano-encapsulated Hyd and Cur are more effective than free forms [20]. However, very limited studies have been performed on the anti-cancer activity of free and nano-encapsulated Hyd, Cur, and Hyd-Cur (combination form), and underlying mechanisms of action.

Therefore, the aim of present study was to investigate anti-proliferative activity of free and poly lactideco-glycolide-co-polyacrylic acid (PLGA-co-PAA) nano-encapsulated Hyd, Cur, and Hyd-Cur combination against PC cell line PANC-1. Moreover, the effects of this compounds were evaluated on mechanisms of apoptosis induction in PANC-1 cancer cells.

\section{Methods}

\section{Hyd and Cur loaded PLGA-PAA copolymer}

The hydrogen terminated poly acrylic acid (PAA-OH) synthesize was performed using radical telomerization of acrylic acid monomers (AAC), agent, Azobisisobutironitrilo (AIBN) as a radical initiator, and mercaptoethanol (ME) as a chain transfer. Also, Poly lactide-co-glycolide-co-polyacrylic acid (PLGAco-PAA) copolymer synthesize was performed using L-lactide (LA) with (PAA-OH) and ring-opening polymerization of glycolide (GA). The PLGA-co-PAA nanoparticles were dissolved in Dimethylsulfoxide (DMSO), and then Hyd or Cur was added and dropped gradually into polymer contained Hyd or Cur solution to make dual drug nanoparticles. The obtained nanoparticles were centrifuged and the supernatant was collected as Hyd or Cur loaded PLGA-co-PAA nanoparticles [20].

\section{Cancer cell line culture}

The PANC-1 cancer cell line was prepared from Cell Bank of Pasteur Institute (Tehran, Iran). The cell culture was performed using Roswell Park Memorial Institute (RPMI)-1640 medium containing 10\% fetal bovine serum (FBS) and $1 \%$ penicillin (100 units $/ \mathrm{mL})$-streptomycin $(100 \mu \mathrm{g} / \mathrm{mL})$. The cells were then incubated at $37^{\circ} \mathrm{C}$ with $95 \%$ humidity and $5 \% \mathrm{CO}_{2}$.

\section{Cell viability assay}


The cancer cells were seeded in a 96 well culture plates $\left(1.5 \times 10^{4}\right.$ cells/well) in $200 \mu \mathrm{L}$ complete medium and then incubated for 24 hours in standard condition. Next, cancer cells were treated with different concentrations of free and nano-encapsulated Hyd, Cur, and Hyd-Cur (10,32, 100, and $320 \mu \mathrm{M})$ for 24, 48, and 72 hours. The cancer cell viability was evaluated using Tetrazolium Micro-culture (MTT) method. The old culture medium was substituted with $200 \mu \mathrm{L}$ complete medium containing $50 \mu \mathrm{L}$ MTT agent solution in PBS $(2 \mathrm{mg} / \mathrm{mL})$ and incubated in standard condition for 4 hours. Then, the culture medium was removed and $200 \mu \mathrm{L}$ of dimethyl sulfoxide (DMSO) was added and incubated for $30 \mathrm{~min}$. The optical density (OD) was measured at $570 \mathrm{~nm}$ using ELISA reader instrument. Finally, viability percentage of treated cancer cells were measured using the following formula: ([treated sample OD / untreated sample OD] × 100) and Graph Pad Prism (v8.0.2) software.

\section{Morphological alterations assay}

The cancer cells were seeded in a 6 well culture plates $\left(1.5 \times 10^{5}\right.$ cells/well $)$ in $2 \mathrm{~mL}$ culture medium and then incubated for 24 hours in standard condition. Next, cancer cells were then treated with Hyd $(19 \mu \mathrm{M})$, Cur $(73 \mu \mathrm{M})$, Hyd-Cur $(7 \mu \mathrm{M})$, nano-Hyd $(9 \mu \mathrm{M})$, nano-Cur $(26 \mu \mathrm{M})$, and nano-Hyd-Cur $(6 \mu \mathrm{M})$, and then incubated for 72 hours. Finally, morphological alterations of cancer cells were monitored by an inverted phase contrast microscope.

\section{Colony formation assay}

The cancer cells were seeded in a 6 well culture plates $\left(3 \times 10^{4}\right.$ cells/ well) in $2 \mathrm{~mL}$ culture medium and incubated in standard condition for 24 hours. The cancer cells were treated with Hyd, Cur, Hyd-Cur, nanoHyd, nano-Cur, and nano-Hyd-Cur, and incubated in standard conditions 8 days. Then, the formed cancer cell colonies were fixed by paraformaldehyde ( $4 \%)$ and stained using crystal violet $(0.1 \%)$. Finally, the colony formation was evaluated and counted using an inverted phase contrast microscope.

\section{Wound healing assay}

The cancer cells were seeded in a 6 well culture plates $\left(5 \times 10^{4}\right.$ cells/well $)$ in $2 \mathrm{~mL}$ culture medium, and then incubated at standard condition for 24 hours. After reaching to $90 \%$ confluence, a scratch was created in the center of each well using a sterile yellow pipette tip and the detached cells were washed away with phosphate-buffered saline. Next, the cancer cells were treated with Hyd, Cur, Hyd-Cur, nanoHyd, nano-Cur, and nano-Hyd-Cur, and incubated in standard conditions at 0-20 hours. Finally, migration of cancer cells was monitored by an inverted phase contrast microscope.

\section{Apoptosis assay}

The cancer cells were seeded in a 6 well culture plates $\left(1.5 \times 10^{5}\right.$ cells/well $)$ in $2 \mathrm{~mL}$ culture medium, and then incubated at standard condition for 24 hours. Next, cancer cells were treated with Hyd, Cur, Hyd-Cur, nano-Hyd, nano-Cur, and nano-Hyd-Cur, and incubated for 72 hours. The cancer cells were detached, washed, and resuspended in binding buffer $(400 \mu \mathrm{L})$ containing annexin V-fluorescein iso-thiocyanate (FITC) $(5 \mu \mathrm{L})$, and propidium iodide $(\mathrm{PI})(10 \mu \mathrm{L})$, and then incubated at room temperature in dark for 15 minutes. Finally, the apoptosis rate of cancer cells was determined using a flow cytometry instrument (Becton Dickinson Bioscience). 


\section{Gene expression assay}

The cancer cells were seeded in a 6 well culture plates $\left(1.5 \times 10^{5}\right.$ cells/well) in $2 \mathrm{~mL}$ culture medium, and then incubated overnight. Then, the cancer cells were treated with Hyd (19 $\mu \mathrm{M})$, Cur (73 $\mu \mathrm{M})$, Hyd-Cur $(7 \mu \mathrm{M})$, nano-Hyd $(9 \mu \mathrm{M})$, nano-Cur $(26 \mu \mathrm{M})$, and nano-Hyd-Cur $(6 \mu \mathrm{M})$, and then incubated for 72 hours. The cancer cells were detached, washed, and resuspended in TRIzol reagent, and total RNA extraction was performed according to the manufacturer's instructions (TaKaRa, Japan). The quality and quantity of the extracted RNA were investigated by electrophoresis on 1\% agarose gel and NanoDrop nstrument. Then, $1 \mu \mathrm{g}$ of total RNA was reversely transcribed into cDNA using oligodT primers. The mRNA expression levels of $M M P 2, M M P 9, B A X, B C L-2$, and Cas-9 genes were evaluated using quantitative RealTime PCR (qRT PCR), and specific oligonucleotide primers (Table 1). The Real Time PCR was performed in $10 \mu \mathrm{L}$ including: $5 \mu \mathrm{L}$ of PCR pre-Mix, $1 \mu \mathrm{L}$ cDNA, $0.5 \mu \mathrm{L}$ forward and reverse primers $(5 \mu \mathrm{M})$. The cycling program was as follows: 1 cycle for initial denaturation at $94^{\circ} \mathrm{C}$ for 1 minute, followed by 40 cycles of denaturation at $94^{\circ} \mathrm{C}$ for 10 seconds, annealing for 30 seconds and extension at $72{ }^{\circ} \mathrm{C}$ for 20 seconds. The ACTB gene ( $\beta$-actin) was considered as endogenous control. The data were analyzed by using comparative $2^{-\Delta \Delta C t}$ threshold cycle.

Table 1

The sequences and characteristics of primers used for detection of genes mRNA expression.

\begin{tabular}{|c|c|c|c|}
\hline Genes & Primers sequences & $T_{m}$ & Products size \\
\hline \multirow[t]{2}{*}{$B A X$} & F-CCCGAGAGGTCTTTTTCCGAG & $60^{\circ} \mathrm{C}$ & \multirow[t]{2}{*}{$155 \mathrm{bp}$} \\
\hline & R-CCAGCCCATGATGGTTCTGAT & $60^{\circ} \mathrm{C}$ & \\
\hline \multirow[t]{2}{*}{$B C L-2$} & F-GATGGGATCGTTGCCTTATG & $56^{\circ} \mathrm{C}$ & \multirow[t]{2}{*}{$223 \mathrm{bp}$} \\
\hline & R-GCGGAACACTTGATTCTGG & $56^{\circ} \mathrm{C}$ & \\
\hline \multirow[t]{2}{*}{ Cas-9 } & F-GCAGGCTCTGGATCTCGGC & $62{ }^{\circ} \mathrm{C}$ & \multirow[t]{2}{*}{152 bp } \\
\hline & R-GCTGCTTGCCTGTTAGTTCGC & $62^{\circ} \mathrm{C}$ & \\
\hline \multirow[t]{2}{*}{ MMP2 } & F-CACATAGTGATGGTTCCCCTGTT & $60^{\circ} \mathrm{C}$ & \multirow[t]{2}{*}{177 bp } \\
\hline & R-CGGCCACTCAGTAGGTGTCTTT & $62^{\circ} \mathrm{C}$ & \\
\hline \multirow[t]{2}{*}{ MMP9 } & F-ATTTCTGCCAGGACCGCTTCTAC & $62^{\circ} \mathrm{C}$ & \multirow[t]{2}{*}{187 bp } \\
\hline & R-ATCCGGCAAACTGGCTCCTTC & $63^{\circ} \mathrm{C}$ & \\
\hline \multirow[t]{2}{*}{ ACTIN } & F-AGAGCTACGAGCTGCCTGAC & $61^{\circ} \mathrm{C}$ & \multirow[t]{2}{*}{184 bp } \\
\hline & R-AGCACTGTGTTGGCGTACAG & $60^{\circ} \mathrm{C}$ & \\
\hline
\end{tabular}

\section{Statistical analysis}


All experiments were repeated three times. The obtained data from three independent experiments were presented as mean \pm standard deviation (SD). The statistical analyses were performed by the Student $t$ test, one-way analysis of variance (ANOVA), and the Tukey (post-hoc) by the Graph Pad Prism software (version 7.0), and differences with $p<0.05$ were considered as significant.

\section{Results}

\section{Cancer cell viability}

Our study indicated that the anti-proliferative effects of free and nano-encapsulated Cur, Hyd, and HydCur were in a time- and concentration-dependent manner. The MTT assay showed that the viability of the treated cancer cells was significantly decreased in high concentrations of all compounds. However, the anti-proliferative activity of free Hyd-Cur and nano-Hyd-Cur was significantly more than other four compounds (Hyd, Cur, nano-Hyd, and nano-Cur) in the same concentrations. Moreover, nanoencapsulation of the Hyd-Cur combination led to increase of anti-proliferative activity. The half maximal inhibitory concentration ( $\left.\mathrm{IC}_{50}\right)$ of used compounds were Hyd $(19 \mu \mathrm{M})$, Cur $(73 \mathrm{mM})$, Hyd-Cur $(7 \mu \mathrm{M})$, nanoHyd $(9 \mu \mathrm{M})$, nano-Cur $(26 \mu \mathrm{M})$, and nano-Hyd-Cur $(6 \mu \mathrm{M})$ on PANC-1 cancer cells after 72 hours (Fig. 1$)$.

\section{Cancer cell morphology}

We observed several morphological alterations in the PANC-1 cancer cells treated with free and nanoencapsulated Cur, Hyd, and Hyd-Cur, which are indicators of programmed cell death. The morphological alterations of treated cancer cells include fragmented nuclei, cell shrinkage, decreased cell size, and membrane damage (Fig. 2A). However, the number of morphological alterations in the treated cancer cells with free Hyd-Cur and nano-Hyd-Cur were significantly more than Hyd, Cur, nano-Hyd, and nano-Cur treated cells (Fig. 2B).

\section{Colony formation}

The colony diameter, colony size, and colony formation of PANC-1 cancer cells were decreased significantly following treatment with free and nano-encapsulated Cur, Hyd, and Hyd-Cur. However, inhibition of colony formation of the PANC-1 cancer cells treated with Hyd-Cur and nano-Hyd-Cur was significantly more than other treatment groups. Moreover, inhibition of colony formation by free and nano-encapsulated Cur, Hyd, and Hyd-Cur was in a dose and time-dependent manner (Fig. 3).

\section{Cancer cell migration}

In the wound healing assay, a significant decrease in the PANC-1 cancer cells migration was observed following the treatment with the free and nano-encapsulated Cur, Hyd, and Hyd-Cur in compared with control cells (Fig. 4A). However, inhibition of migration of the PANC-1 cancer cells treated with Hyd-Cur and nano-Hyd-Cur was significantly more than other treatment groups. Moreover, wound healing assay showed that inhibition of migration of free and nano-encapsulated Cur, Hyd, and Hyd-Cur were as a dose and time-dependent manner (Fig. 4B).

\section{Cancer cell apoptosis}


Our study indicated that both early and late apoptosis rate were increased significantly in PANC-1 cancer cells treated with free and nano-encapsulated Cur, Hyd, and Hyd-Cur compared to the untreated cells. The total apoptosis rate of the treated cancer cells was Hyd (21\%), Cur (26\%), Hyd-Cur (31\%), nano-Hyd (31\%), nano-Cur (30\%), and nano-Hyd-Cur (41\%). However, the total apoptosis rate of the cancer cells treated with free Hyd-Cur and nano-encapsulated Hyd-Cur treated cancer cells was significantly more than other treatment groups (Fig. 5).

\section{Expression of migration related genes}

The mRNA expression levels of MMP2 and MMP9 genes were significantly decreased in treated PANC-1 cancer cells with free and nano-encapsulated Cur, Hyd, and Hyd-Cur. However, regulation of migration related genes expression in the treated cancer cells with Hyd-Cur and nano-Hyd-Cur were significantly more profound than cells treated with other compounds (Fig. 6A, B).

\section{Expression of apoptosis related genes}

The mRNA expression of the apoptosis related $B A X$ and Cas-9 gene was significantly increased in PANC1 cancer cells treated with free and nano-encapsulated Cur, Hyd, and Hyd-Cur (Fig. 6C, D). Moreover, the mRNA expression of the apoptosis related $B C L-2$ genes was significantly decreased in cancer cells treated with free and nano-encapsulated Cur, Hyd, and Hyd-Cur (Fig. 6E). However, regulation of apoptosis related genes expression in the treated cancer cells with Hyd-Cur and nano-Hyd-Cur were significantly more profound than other treatment groups.

\section{Discussion}

$P C$ is a deadliest cancer worldwide, which surgical resection remains the only curative therapeutic treatment $[21,22]$. The chemotherapy following surgical method has been used for treatment of patients with advanced PC. However, chemotherapy is associated with several side effects and poor survival [23, 24]. In order to improve the overall survival of patients with advanced PC, many studies combined various chemotherapy drugs with different natural agents, although the results were not encouraging $[25,26]$. Therefore, new alternative therapies involving natural compounds with minimal toxicity, such as Cur and Hyd, have been considered for treatment of PC. However, short half-life and low solubility of Hyd and Cur in aquatic and physiological environments is the main cause of limited use of these compounds [18]. Therefore, in the present study we increased half-life and solubility of Hyd and Cur using nanoencapsulation by PLGA-PAA copolymer.

We observed that Hyd, Cur, and its combinations (Hyd-Cur) significantly decreased the PC cells viability, proliferation, metabolic activities, migration, and colony formation. Moreover, Hyd, Cur, and Hyd-Cur significantly increased the morphological alterations in PC cells, includes cell shrinkage, chromatin condensation, and apoptotic bodies formation, which clearly showed that the inhibition of PC cells may be due to apoptosis induction. Our study showed that the cytotoxic effects of nano-encapsulated Hyd, Cur, and Hyd-Cur were significantly more than its free form. 
The high lethality in patients with cancer is due to metastasis and tumor growth at distant tissues [27]. In this study, wound healing assays demonstrated that migration of PC cells treated with free and nanoencapsulated Hyd-Cur combination were decreased more significantly, as compared Hyd or Cur monotherapy. Moreover, migration of PC cells treated with nano-encapsulated Hyd, Cur, and Hyd-Cur decreased more significantly, as compared its free form. To investigate whether free and nanoencapsulated Hyd, Cur, and Hyd-Cur decrease metastasis in PC cells, we evaluated involved genes expression in metastasis of cancer cells. Our results showed that free and nano-encapsulated Hyd, Cur, and Hyd-Cur significantly inhibited the mRNA levels of MMP2 and MMP9 in PC cells. However, the mRNA levels of $M M P 2$ and $M M P 9$ in PC cells treated with nano-encapsulated Hyd-Cur were decreased more significantly, as compared to other treatment groups. These results showed that free and nanoencapsulated Hyd, Cur, and Hyd-Cur may inhibit the migration of PC cells through downregulation of $M M P 2$ and $M M P 9$ genes.

The apoptosis induction is one of the most important mechanisms of cancer treatment with chemotherapeutic drugs. We demonstrated that the apoptosis rate of the PC cells treated with free and nano-encapsulated Hyd, Cur, and Hyd-Cur were increased, as compared with untreated PC cells. However, the apoptosis rates of $\mathrm{PC}$ cells treated with nano-encapsulated Hyd-Cur indicated more significant increase in comparison with free Hyd or Cur monotherapies. Previous studies reported that Hyd and Cur increased apoptosis rate in several cancer cells $[28,29]$. Several factors have been identified in the regulation of apoptotic pathways. In particular, the evidence showed that Hyd and Cur are able to downregulate and up-regulate the anti-apoptotic and pro-apoptotic factors, respectively [30, 31]. In this regards, we demonstrated that Hyd and Cur were able to down-regulate the mRNA expression of BCL-2 gene, as an anti-apoptotic gene. Moreover, it was shown Hyd and Cur up-regulated the mRNA expression of $B A X$ and Cas-9 genes, as pro-apoptotic genes. As expected, nano-encapsulated and combined treatment with Hyd and Cur resulted in the favor of apoptotic pattern of $B C L-2, B A X$, and Cas-9 genes mRNA expression. These results indicated that free and nano-encapsulated Hyd, Cur, and Hyd-Cur could inhibit PC cells viability and proliferation through induction of apoptotic pathways.

\section{Conclusion}

The current study represents a novel combination and nano-encapsulation chemotherapeutic approach to treatment of patients with PC. It was shown that, nano-encapsulation enhanced the anti-proliferative activity of Hyd and Cur against PC cells through induction of apoptotic. Therefore, the nanoencapsulation and combined Hyd-Cur can be used in the future to control and even treatment of patients with PC. However, further studies are required to identify the enhanced anti-growth mechanisms of free and nano-encapsulated Hyd, Cur, and Hyd-Cur to better management of patients with PC and prescription of lower doses of chemotherapeutic agents.

\section{Abbreviations}


PC: Pancreatic Cancer; Hyd: Hydroxytyrosol; Cur: Curcumin; PLGA-co-PAA: Poly Lactide-co-Glycolide-coPolyacrylic Acid; PAA-OH: Hydrogen Terminated Poly Acrylic Acid; AAc: Acrylic Acid Monomers; AIBN:

Azobisisobutironitrilo; LA: L-Lactide; ME: Mercaptoethanol; DMSO: Dimethylsulfoxide; RPMI: Roswell Park Memorial Institute; FBS: Fetal Bovine Serum; OD: Optical Density; FITC: Annexin V-Fluorescein Iso-

Thiocyanate; PI: Propidium lodide; qRT-PCR: Real-Time PCR; SD: Standard Deviation; ANOVA: Analysis of Variance; $\mathrm{IC}_{50}$ : Half Maximal Inhibitory Concentration.

\section{Declarations}

\section{Acknowledgements}

Not applicable.

\section{Authors' contributions}

All authors had an equal role in design, work, statistical analysis, and manuscript writing.

\section{Funding}

Not applicable.

\section{Availability of data and materials}

All the data generated or analyzed during this study are included in this published article.

\section{Ethics approval and consent to participate}

Not applicable.

\section{Consent for publication}

Not applicable.

\section{Competing interests}

All authors declare that there is no conflict of interests in this study.

\section{References}

1. McGuigan A, Kelly P, Turkington RC, Jones C, Coleman HG, McCain RS. Pancreatic cancer: A review of clinical diagnosis, epidemiology, treatment and outcomes. World journal of gastroenterology. 2018;24(43):4846.

2. Lambert A, Schwarz L, Borbath I, Henry A, Van Laethem JL, Malka D, Ducreux M, Conroy T. An update on treatment options for pancreatic adenocarcinoma. Therapeutic advances in medical oncology. 
2019; 11:1758835919875568.

3. Firouzi Amoodizaj F, Baghaeifar S, Taheri E, Farhoudi Sefidan Jadid M, Safi M, Seyyed Sani N, Hajazimian S, Isazadeh A, Shanehbandi D. Enhanced anticancer potency of doxorubicin in combination with curcumin in gastric adenocarcinoma. Journal of Biochemical and Molecular Toxicology. 2020:e22486.

4. Hajazimian S, Maleki M, Mehrabad SD, Isazadeh A. Human Wharton's jelly stem cells inhibit endometriosis through apoptosis induction. Reproduction. 2020;159(5):549-58.

5. Wang TY, Chen JX. Effects of Curcumin on Vessel Formation Insight into the Pro-and Antiangiogenesis of Curcumin. Evidence-Based Complementary and Alternative Medicine. 2019;2019.

6. Tan BL, Norhaizan ME. Curcumin combination chemotherapy: the implication and efficacy in cancer. Molecules. 2019;24(14):2527.

7. Safarzadeh E, Shotorbani SS, Baradaran B. Herbal medicine as inducers of apoptosis in cancer treatment. Adv Pharm Bull. 2014;4(1):421.

8. Koohpar ZK, Entezari M, Movafagh A, Hashemi M. Anticancer activity of curcumin on human breast adenocarcinoma: role of Mcl-1 gene. Iranian journal of cancer prevention. 2015;8(3).

9. Shiri S, Alizadeh AM, Baradaran B, Farhanghi B, Shanehbandi D, Khodayari S, Khodayari H, Tavassoli A. Dendrosomal curcumin suppresses metastatic breast cancer in mice by changing $\mathrm{m} 1 / \mathrm{m} 2$ macrophage balance in the tumor microenvironment. Asian Pac J Cancer Prev. 2015;16(9):3917-22.

10. Ghaffari M, Dehghan G, Baradaran B, Zarebkohan A, Mansoori B, Soleymani J, Dolatabadi JE, Hamblin MR. Co-delivery of curcumin and Bcl-2 siRNA by PAMAM dendrimers for enhancement of the therapeutic efficacy in HeLa cancer cells. Colloids Surf B Biointerfaces. 2020;188:110762.

11. Boss A, Bishop KS, Marlow G, Barnett MP, Ferguson LR. Evidence to support the anti-cancer effect of olive leaf extract and future directions. Nutrients. 2016;8(8):513.

12. Bulotta S, Celano M, Lepore SM, Montalcini T, Pujia A, Russo D. Beneficial effects of the olive oil phenolic components oleuropein and hydroxytyrosol: focus on protection against cardiovascular and metabolic diseases. Journal of translational medicine. 2014;12(1):219.

13. Zhao B, Ma Y, Xu Z, Wang J, Wang F, Wang D, Pan S, Wu Y, Pan H, Xu D, Liu L. Hydroxytyrosol, a natural molecule from olive oil, suppresses the growth of human hepatocellular carcinoma cells via inactivating AKT and nuclear factor-kappa B pathways. Cancer letters. 2014;347(1):79-87.

14. Calderón-Montaño JM, Madrona A, Burgos-Moron E, Orta ML, Mateos S, Espartero JL, López-Lázaro M. Selective cytotoxic activity of new lipophilic hydroxytyrosol alkyl ether derivatives. Journal of agricultural and food chemistry. 2013;61(21):5046-53.

15. Rosignoli P, Fuccelli R, Sepporta MV, Fabiani R. In vitro chemo-preventive activities of hydroxytyrosol: The main phenolic compound present in extra-virgin olive oil. Food \& function. 2016;7(1):301-7.

16. Swider E, Koshkina O, Tel J, Cruz LJ, de Vries IJ, Srinivas M. Customizing poly (lactic-co-glycolic acid) particles for biomedical applications. Acta biomaterialia. 2018;73:38-51. 
17. Vilaplana-Pérez C, Auñón D, García-Flores LA, Gil-Izquierdo A. Hydroxytyrosol and potential uses in cardiovascular diseases, cancer, and AIDS. Frontiers in nutrition. 2014; 1:18.

18. Kashi TS, Eskandarion S, Esfandyari-Manesh M, Marashi SM, Samadi N, Fatemi SM, Atyabi F, Eshraghi S, Dinarvand R. Improved drug loading and antibacterial activity of minocycline-loaded PLGA nanoparticles prepared by solid/oil/water ion pairing method. International journal of nanomedicine. 2012;7:221.

19. Vahedian V, Asadi A, Esmaeili P, Zamani S, Zamani R, Hajazimian S, Isazadeh A, Shanehbandi D, Maroufi NF. Anti-inflammatory activity of emu oil-based nanofibrous scaffold through downregulation of IL-1, IL-6, and TNF-a pro-inflammatory cytokines. Hormone Molecular Biology and Clinical Investigation. 2020;20190052.

20. Ahmadi E, Zarghami N, Jafarabadi MA, Alizadeh L, Khojastehfard M, Yamchi MR, Salehi R. Enhanced anticancer potency by combination chemotherapy of $\mathrm{HT}-29$ cells with biodegradable, $\mathrm{pH}$-sensitive nanoparticles for co-delivery of hydroxytyrosol and doxorubicin. Journal of Drug Delivery Science and Technology. 2019;51:721-35.

21. Siegel R, Naishadham D. jemal A: Cancer statistics, 2013. CA: A Cancer Journal. 2013;63:11-30.

22. Stathis A, Moore MJ. Advanced pancreatic carcinoma: current treatment and future challenges. Nature reviews Clinical oncology. 2010;7(3):163.

23. Maroufi NF, Vahedian V, Akbarzadeh M, Mohammadian M, Zahedi M, Isazadeh A, Pouremamali $F$, Taefehshokr S, Heidari M, Rashidi M, Nouri M. The apatinib inhibits breast cancer cell line MDA-MB231 in vitro by inducing apoptosis, cell cycle arrest, and regulating nuclear factor-KB (NF-KB) and mitogen-activated protein kinase (MAPK) signaling pathways. Breast Cancer. 2020:1-8.

24. Maroufi NF, Vahedian V, Hemati S, Rashidi M, Akbarzadeh M, Zahedi M, Pouremamali F, Isazadeh A, Taefehshokr S, Hajazimian S, Seraji N. Targeting cancer stem cells by melatonin: Effective therapy for cancer treatment. Pathology-Research and Practice. 2020:152919.

25. Taheri E, Ghorbani S, Safi M, Seyyed Sani N, Firouzi Amoodizaj F, Heidari M, Hajazimian S, Isazadeh A, Heidari M. Inhibition of Colorectal Cancer Cell Line CaCo-2 by Essential Oil of Eucalyptus Camaldulensis Through Induction of Apoptosis. Acta Medica Iranica. 2020;58(6).

26. Mahdavi S, Kheyrollahi M, Sheikhloei $H$, Isazadeh A. Antibacterial and Antioxidant Activities of Essential Oil on Food Borne Bacteria. The Open Microbiology Journal. 2019;13(1):81-85.

27. Soheilyfar S, Velashjerdi Z, Hajizadeh YS, Maroufi NF, Amini Z, Khorrami A, Azimian SH, Isazadeh A, Taefehshokr S, Taefehshokr N. In vivo and in vitro impact of miR-31 and miR-143 on the suppression of metastasis and invasion in breast cancer. J BUON. 2018;23(5):1290-6.

28. Tutino V, Caruso MG, Messa C, Perri E, Notarnicola M. Antiproliferative, antioxidant and antiinflammatory effects of hydroxytyrosol on human hepatoma HepG2 and Hep3B cell lines. Anticancer research. 2012;32(12):5371-7.

29. Yang H, Huang S, Wei Y, Cao S, Pi C, Feng T, Liang J, Zhao L, Ren G. Curcumin enhances the anticancer effect of 5-fluorouracil against gastric cancer through down-regulation of COX-2 and NFKB signaling pathways. Journal of Cancer. 2017;8(18):3697. 
30. Akkoç Y, Berrak Ö, Arısan ED, Obakan P, Çoker-Gürkan A, Palavan-Ünsal N. Inhibition of PI3K signaling triggered apoptotic potential of curcumin which is hindered by Bcl-2 through activation of autophagy in MCF-7 cells. Biomedicine \& Pharmacotherapy. 2015;71:161-71.

31. Toteda G, Lupinacci S, Vizza D, Bonofiglio R, Perri E, Bonofiglio M, Lofaro D, La Russa A, Leone F, Gigliotti P, Cifarelli RA. High doses of hydroxytyrosol induce apoptosis in papillary and follicular thyroid cancer cells. Journal of endocrinological investigation. 2017;40(2):153-62.

Figures
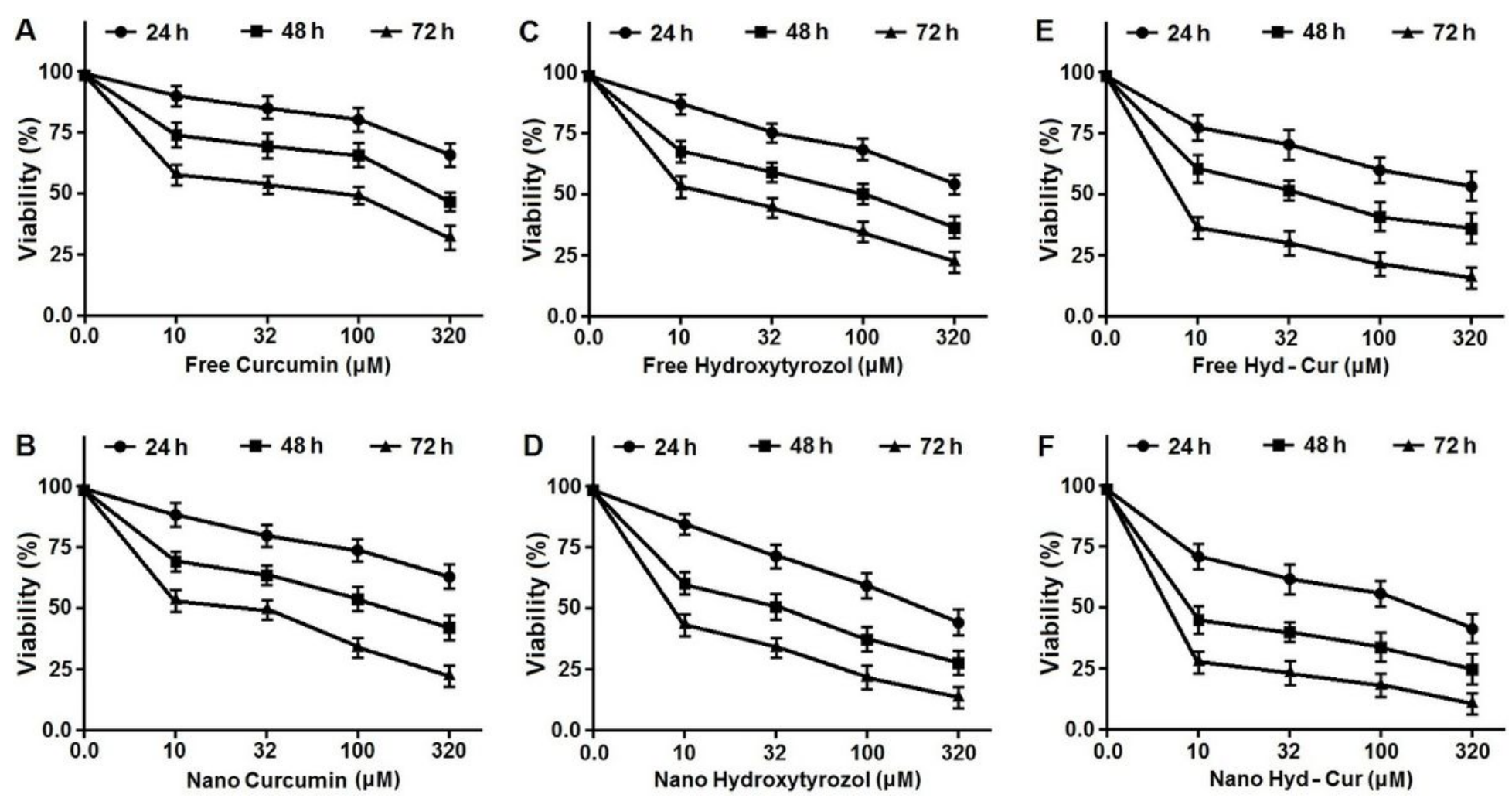

Figure 1

The inhibitory effects of free Cur (A), free Hyd (B), free Hyd-Cur (C), nano Cur (D), nano Hyd (E), and nano Hyd-Cur $(F)$ on viability of PANC-1 cell line in 24-72 hours. 


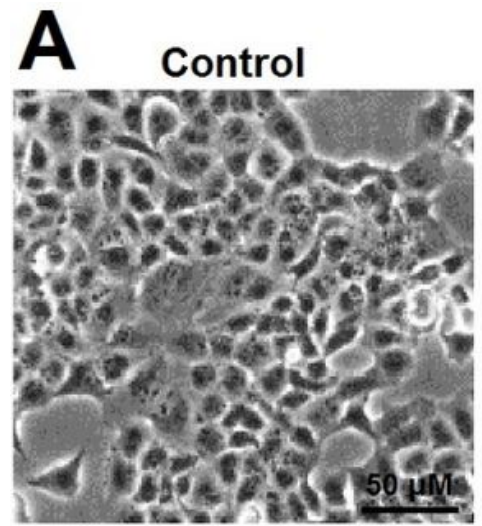

Free Hyd $(19 \mu \mathrm{M})$

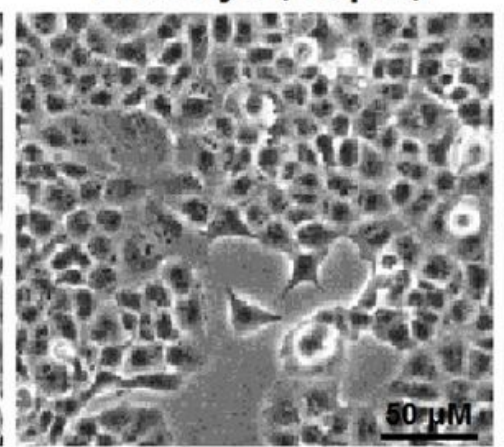

Control
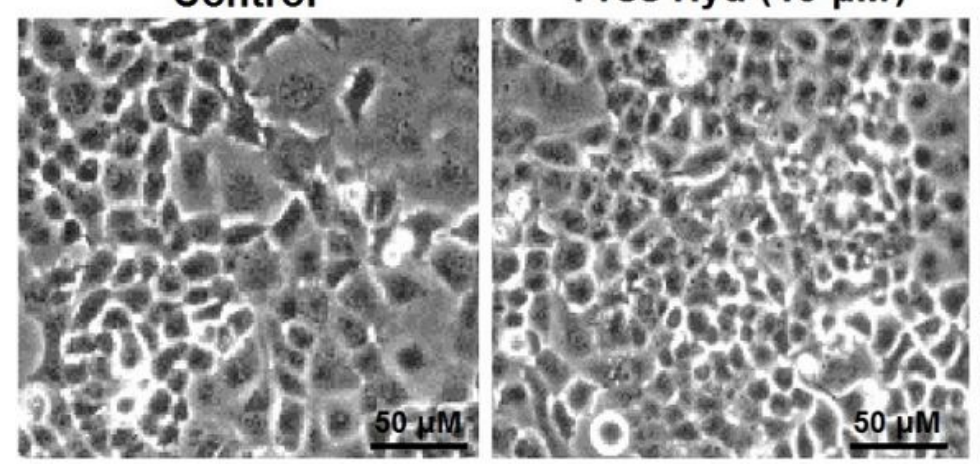

Free Cur $(73 \mu \mathrm{M})$

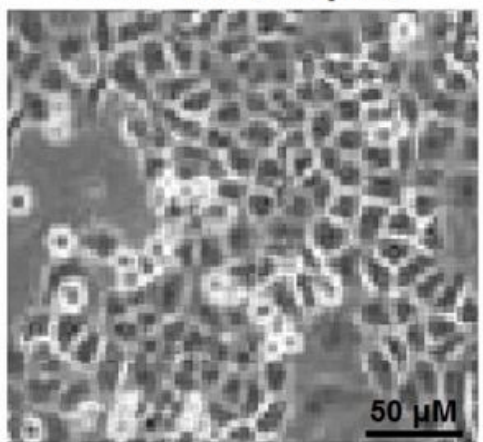

Free Cur $(73 \mu \mathrm{M})$
Free Hyd-Cur $(7 \mu \mathrm{M})$

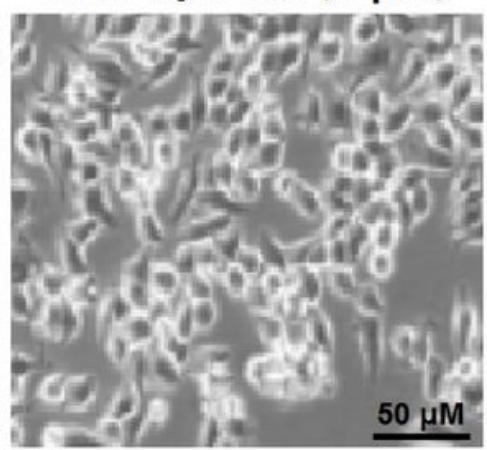

Free Hyd-Cur $(7 \mu \mathrm{M})$
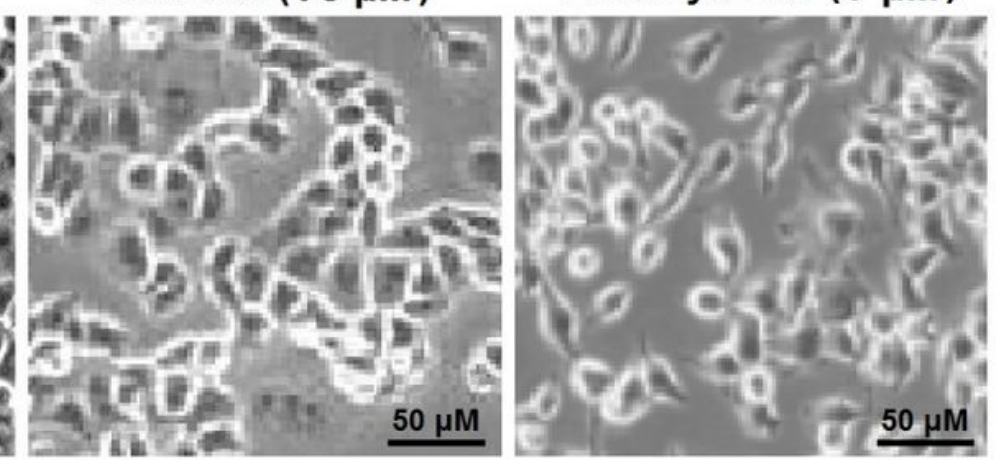

B

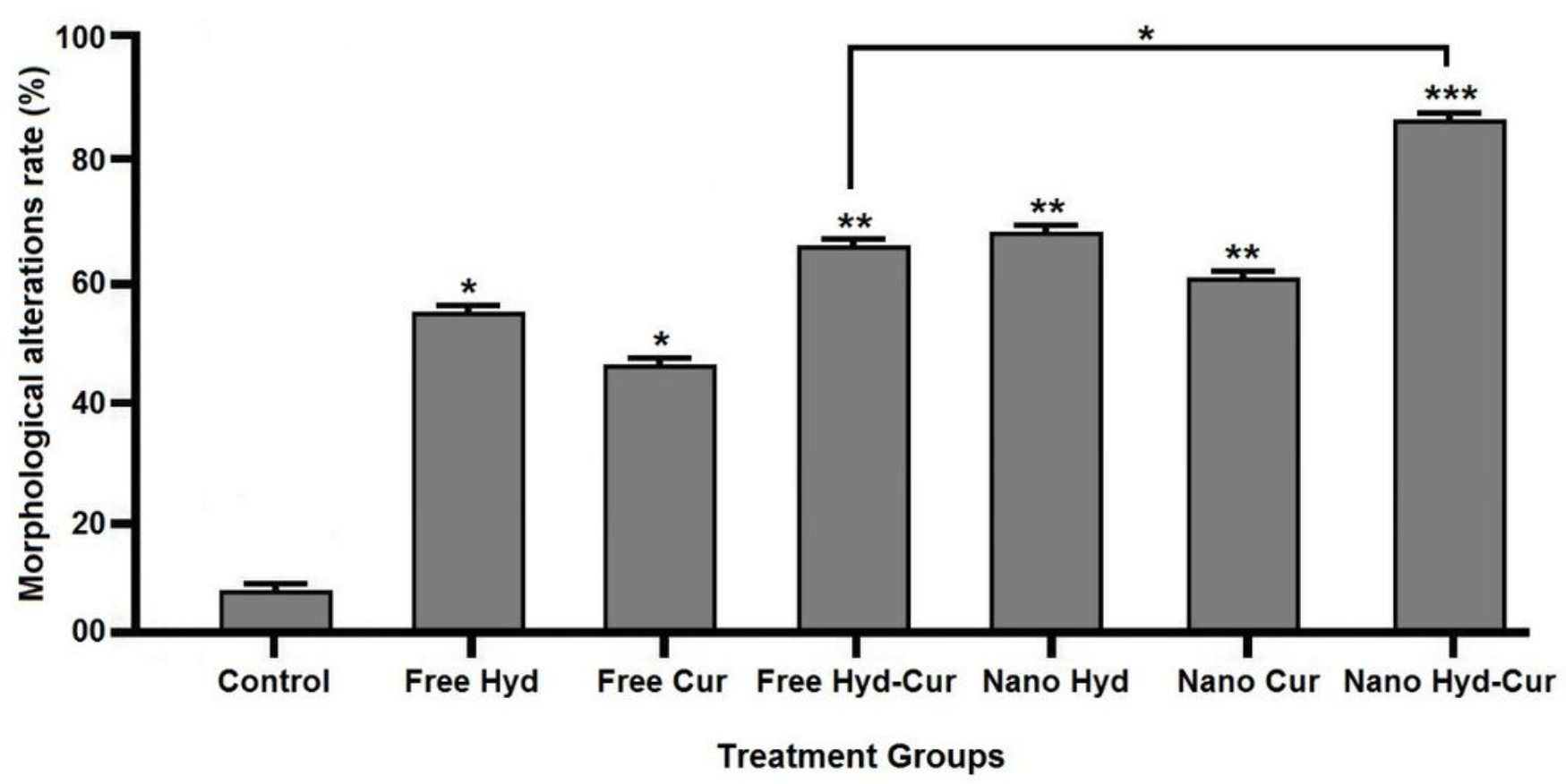

Figure 2

The morphological alteration of PANC-1 cell line treated with free Hyd $(19 \mu \mathrm{M})$, free Cur $(73 \mu \mathrm{M})$, free HydCur $(7 \mu \mathrm{M})$, nano Hyd $(9 \mu \mathrm{M})$, nano Cur $(26 \mu \mathrm{M})$, and nano Hyd-Cur $(6 \mu \mathrm{M})$ for 72 hours. Treatment of cancer cells with nano Hyd-Cur leads to significant increase in the morphological alteration related to apoptosis. 

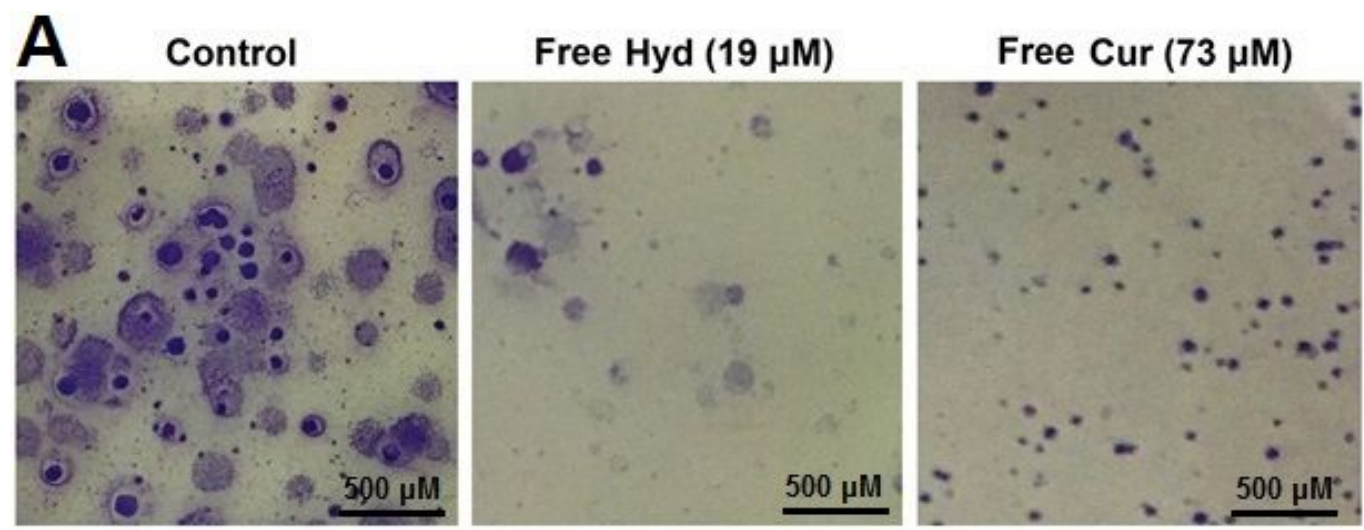

Free Hyd-Cur (7 $\mu \mathrm{M})$
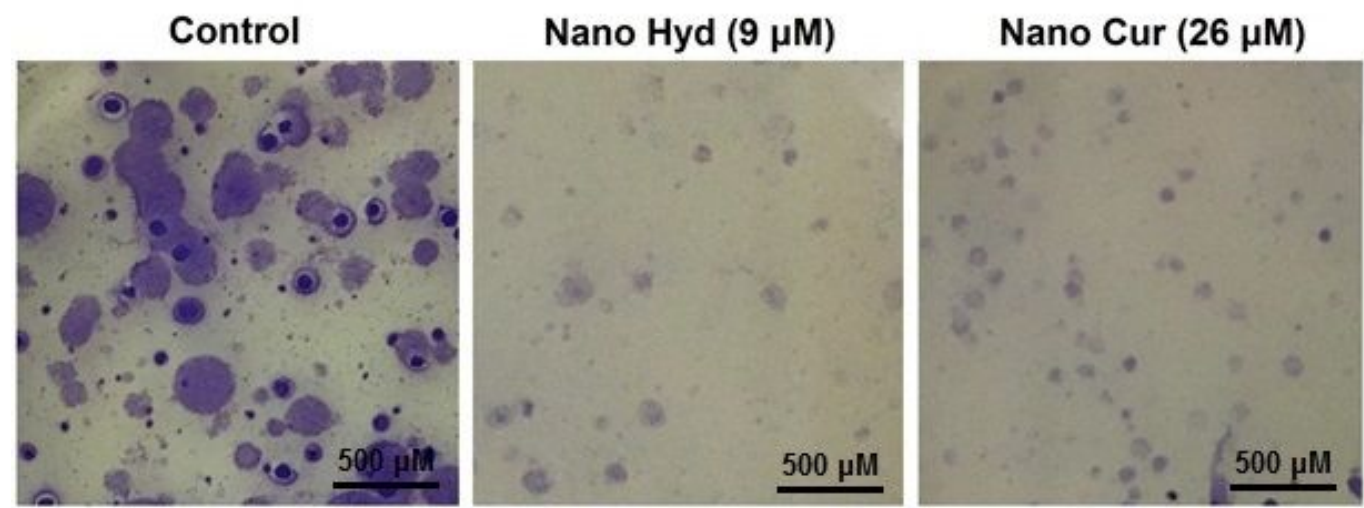

Nano Hyd-Cur $(6 \mu \mathrm{M})$

$500 \mu \mathrm{M}$

B

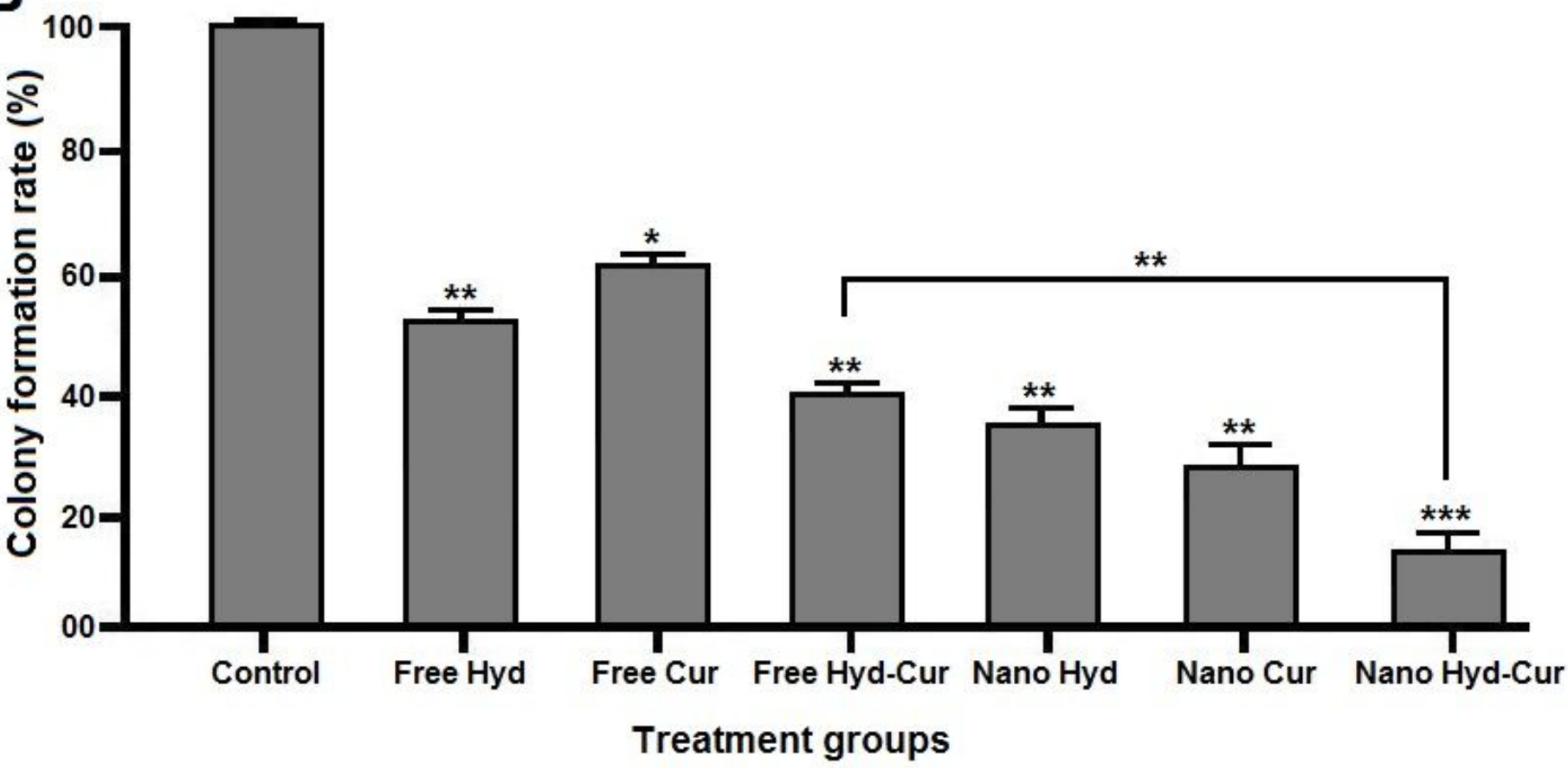

Figure 3

The colony formation of PANC-1 cell line treated with free Hyd $(19 \mu \mathrm{M})$, free Cur $(73 \mu \mathrm{M})$, free Hyd-Cur $(7$ $\mu \mathrm{M})$, nano Hyd $(9 \mu \mathrm{M})$, nano Cur $(26 \mu \mathrm{M})$, and nano Hyd-Cur $(6 \mu \mathrm{M})$. Treatment of cancer cells with nano Hyd-Cur leads to significant decrease in the size and number of colonies. 
A
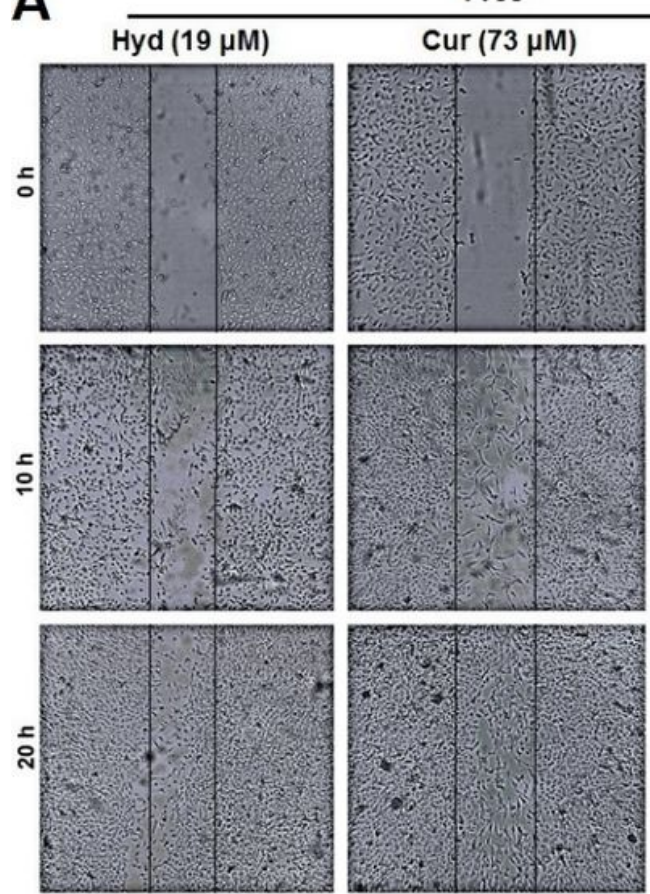

B

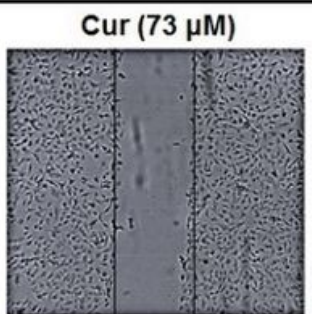

Hyd-Cur $(7 \mu \mathrm{M})$
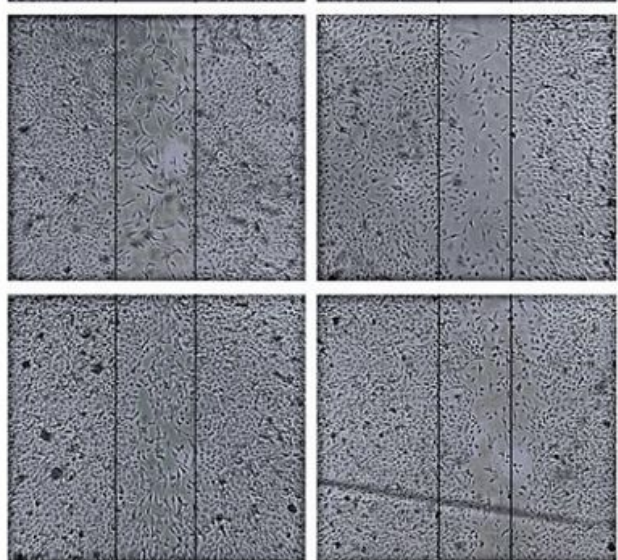

Nano

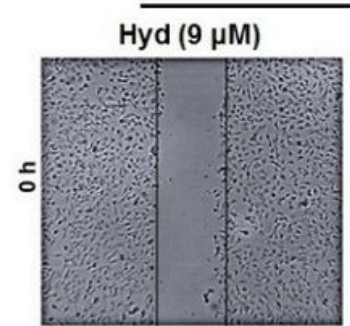

Cur $(26 \mu \mathrm{M})$

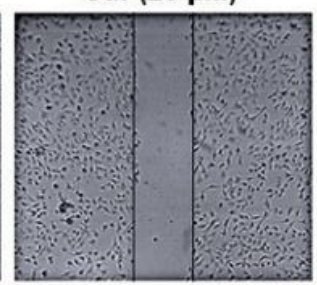

Hyd-Cur $(6 \mu \mathrm{M})$
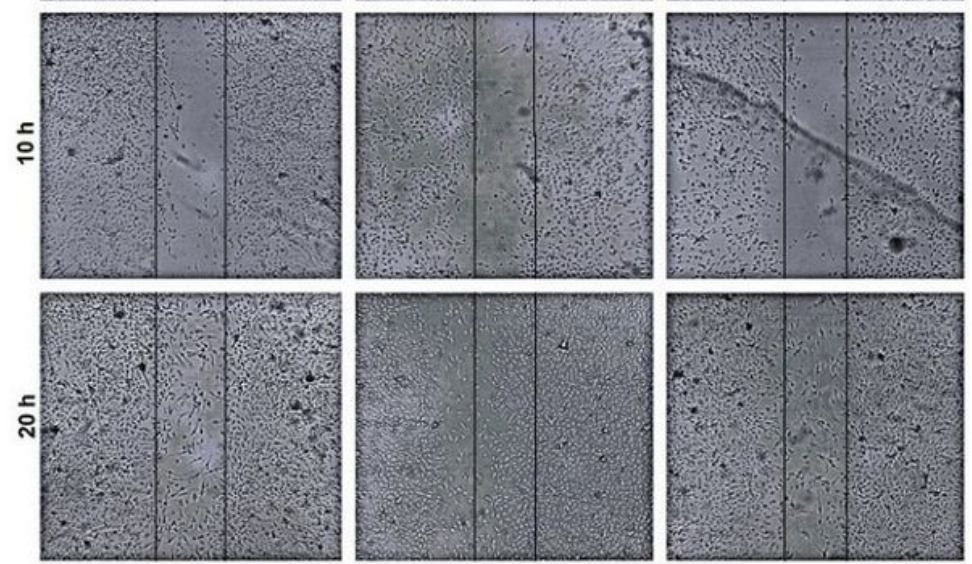
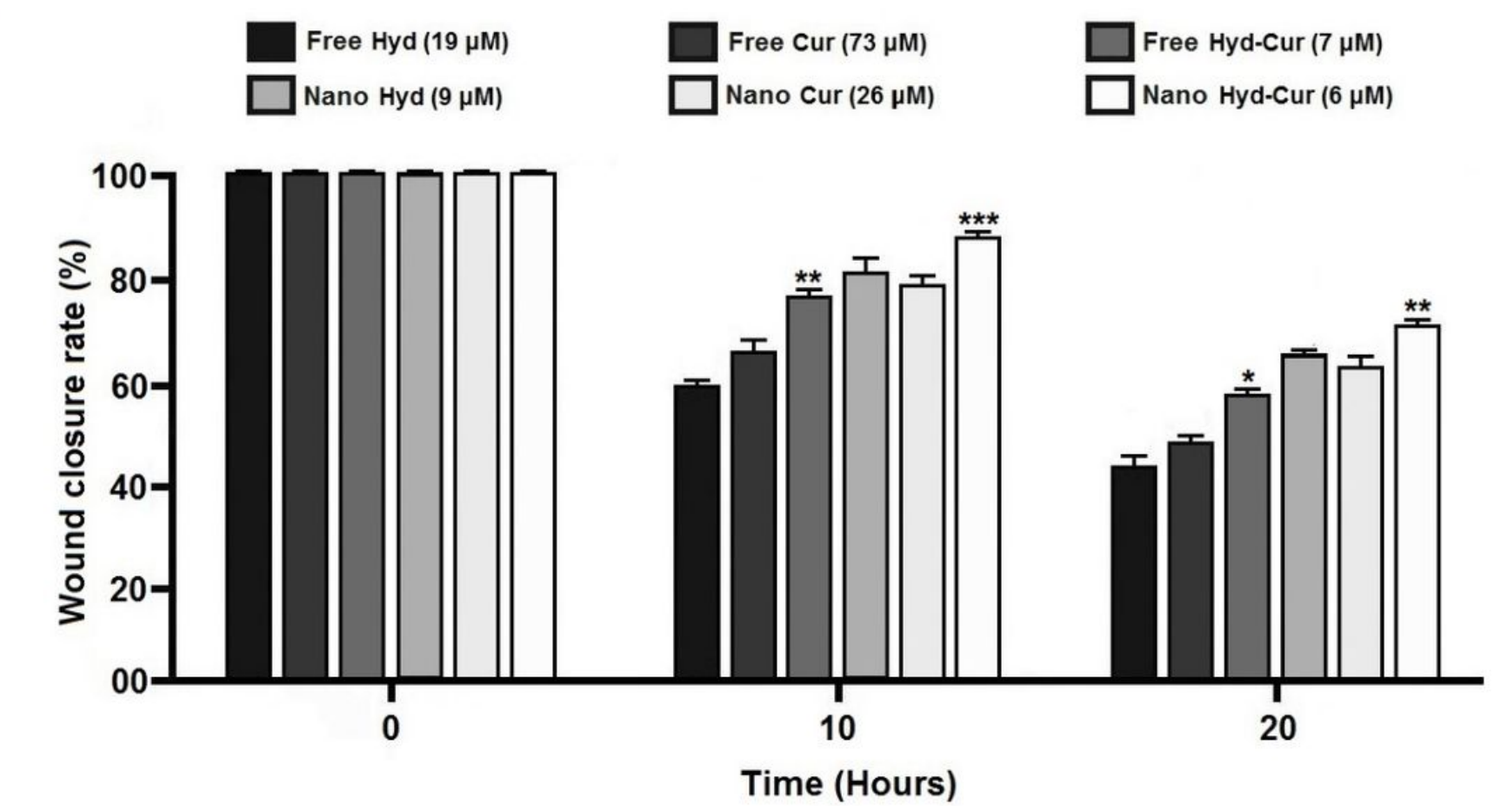

Figure 4

The PANC-1 cell line migration was evaluated with scratch wound healing assay following treatment with free Hyd $(19 \mu \mathrm{M})$, free Cur $(73 \mu \mathrm{M})$, free Hyd-Cur $(7 \mu \mathrm{M})$, nano Hyd (9 $\mu \mathrm{M})$, nano Cur $(26 \mu \mathrm{M})$, and nano Hyd-Cur $(6 \mu \mathrm{M})$ for 20 hours $(A)$. The inhibition of migration in the cancer cells treated with nano Hyd-Cur was significantly more as compared with other treatments $(B)$. 

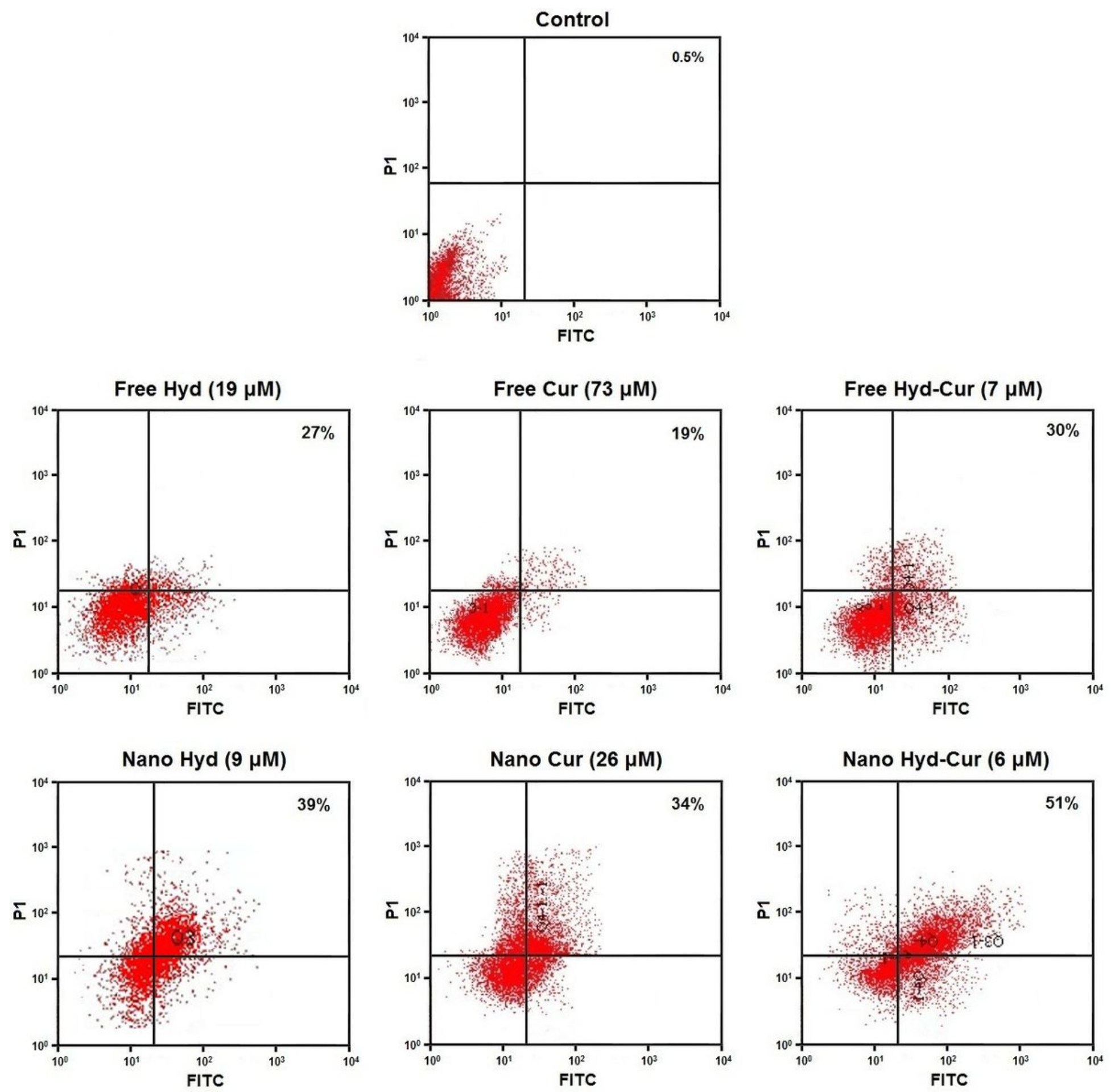

Figure 5

Quantification of apoptosis by annexin V-FITC/PI assay in PANC-1 cell line treated with free Hyd (19 $\mu \mathrm{M})$, free Cur $(73 \mu \mathrm{M})$, free Hyd-Cur $(7 \mu \mathrm{M})$, nano Hyd $(9 \mu \mathrm{M})$, nano Cur $(26 \mu \mathrm{M})$, and nano Hyd-Cur $(6 \mu \mathrm{M})$. The induction of apoptosis in the PANC-1 cells treated with nano Hyd-Cur was significantly more than other treatments. 

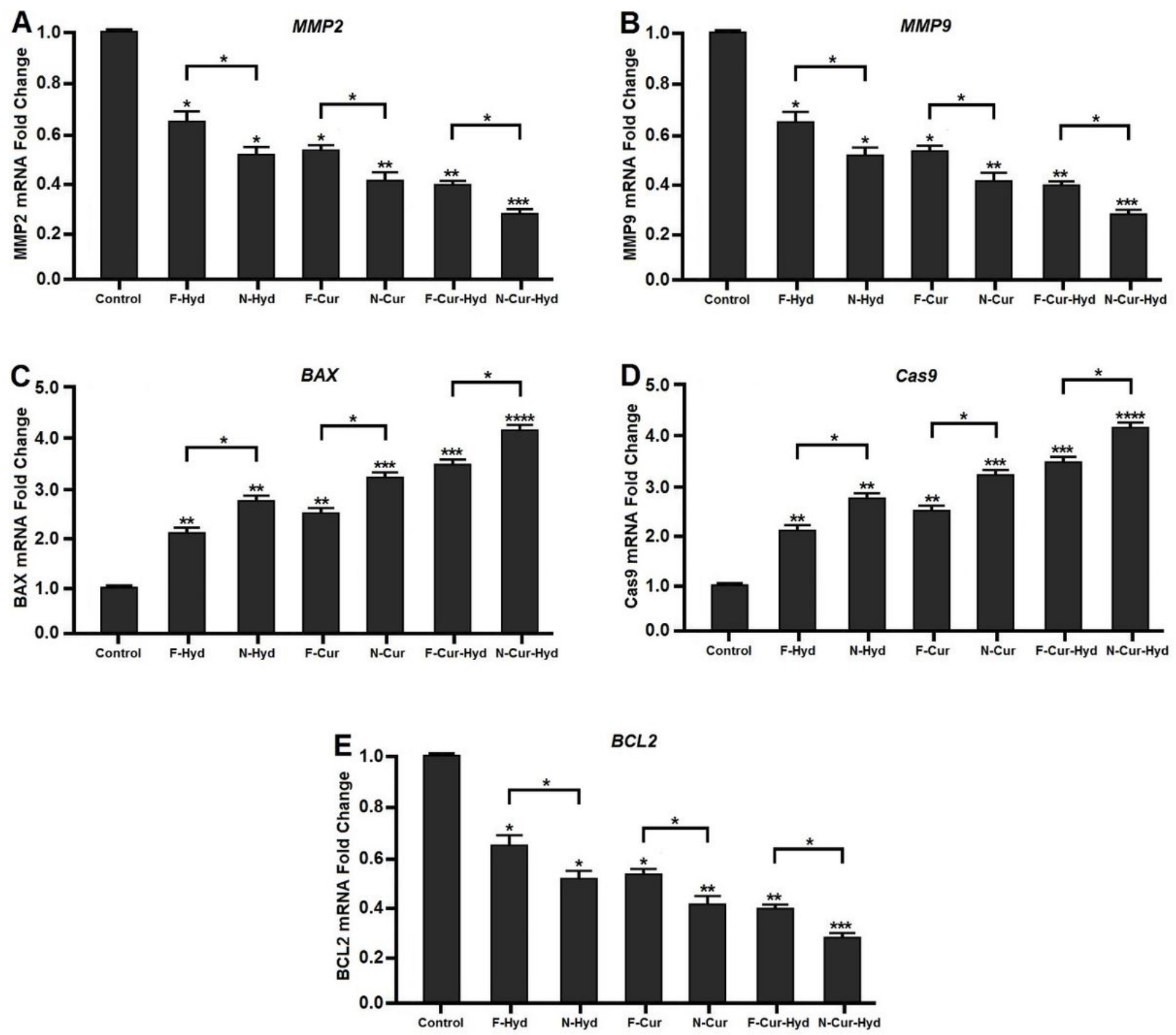

Figure 6

The mRNA expression analysis of migration related MMP2 (A) and MMP9 genes (B) and apoptosis related BAX (C), BCL2 (D), and Cas-9 (E) genes by qRT-PCR following treatment with free Hyd $(19 \mu \mathrm{M})$, free Cur $(73 \mu \mathrm{M})$, free Hyd-Cur $(7 \mu \mathrm{M})$, nano Hyd $(9 \mu \mathrm{M})$, nano Cur $(26 \mu \mathrm{M})$, and nano Hyd-Cur $(6 \mu \mathrm{M})$ in PANC-1 cell line. The regulation of migration, and apoptosis related genes expression in the PANC-1 cells treated with nano Hyd-Cur was significantly more than other treatments. 